\title{
Effects of neonatal thyroid hormone stimulation and differential preweaning rearing on spatial discrimination learning in rats
}

\author{
PER-OLOW SJÖDÉN \\ Neurophysiological Laboratory, Ulleråker Hospital, Uppsala University, S-75017, Uppsala, Sweden
}

\begin{abstract}
Rats injected with a mixture of tri-iodothyronine $\left(\mathrm{T}_{3}\right)$ and thyroxine $\left(\mathrm{T}_{4}\right)$ on Day 4 after birth (T group) were raised during the preweaning period, half in an enriched (E) and half in an impoverished (I) environment. Saline-injected controls (C group) were subjected to identical rearing conditions. On Day 165, spatial position (left-right) discrimination training in a water-filled T-maze (original training: OT) was started. After OT, three position reversals (R1, R2, and R3) were employed. The results indicate that the $\mathrm{T}$ group was inferior to the $\mathrm{C}$ group only for $\mathrm{R} 1$, but superior with respect to mean final error trials during OT and R2. Thyroid Hormone by Rearing Condition interactions were found for (1) the number of trials to criterion, due to a facilitation of learning by neonatal thyroid hormone in the I condition only, and (2) for the number of initial perseverative errors in the R1 phase. It is concluded that the concept of "inferior learning ability" as applied to neonatally thyroid hormone-treated rats is not appropriate. The performance difference between such rats and controls is not only determined by their neonatal hormone treatment, but also by their preweaning rearing environment and by the relative difficulty of the learning test used.
\end{abstract}

The long-term behavioral effects of neonatal thyroxine $\left(T_{4}\right)$ and tri-idothyronine $\left(T_{3}\right)$ stimulation of rats have been demonstrated in at least two respects: (1) An elevated rate of locomotor activity. This has been reported for both sexes of rats at various ages up to 200 days (Lát \& Gollovà-Hémon, 1969; Pelt, 1972; Rastogi \& Singhal, 1976; Schapiro, 1966, 1968, 1971; Sjödén \& Söderberg, 1976, in press; Stone \& Greenough, 1975). Also, neo- $T_{3}+T_{4^{-}}$ stimulated females (given a mixture of $T_{3}$ and $T_{4}$ ) do not exhibit a normal adult pattern of habituation of open-field ambulation and rearing over minutes and days of testing (Sjödén \& Söderberg, in press). (2) Deficiencies of adult learning. The behavior of neo- $T_{3}$ and neo- $T_{4}$ rats has been studied in a number of learning tests. These include the Hebb-Williams maze (Eayrs, 1964; Pelt, 1972), a modified closed-field test (Davenport \& Gonzalez, 1973; Davenport, Hagquist, \& Hennies, 1975), a Y-shaped water-maze (Schapiro, 1968), and the Lashley III maze (Schapiro, 1968; Stone \& Greenough, 1975). With one exception (Pelt, 1972), all workers have shown neo- $T_{3}$ and $-T_{4}$ rats to be inferior to controls in adult learning. The results from studies of active avoidance behavior are inconclusive, since Schapiro and Norman (1967) reported a facilitation of one-way avoidance by neonatal thyroxine at 1618 days, whereas Davenport and Gonzalez (1973)

Thanks are due to Professor U. Söderberg and Dr. H. Åsberg for continuous support and valuable suggestions in the present work. This work was supported in part by grants from the University of Uppsala. could not replicate this result in a two-way test. Recently, however, Stone and Greenough (1975) found a facilitation of one-way avoidance by neonatal $\mathrm{T}_{4}$ administration. Passive avoidance learning in juvenile and adolescent animals has been shown deficient after neo- $T_{4}$ stimulation (Davenport \& Gonzalez, 1973; Stone \& Greenough, 1975).

A number of explanations of the learning deficits have been proposed. These range from hypotheses based on the neuroanatomical (Balázs, Kovács, Cocks, Johnson, \& Eayrs, 1971; Nicholson \& Altman, 1972a, b), endocrinological (Bakke \& Lawrence, 1966; Bakke, Lawrence, \& Wilber, 1974; Eayrs, 1968; Eayrs \& Holmes, 1964; Schreiber \& Kmentová, 1965/66), motivational (Davenport \& Gonzalez, 1973), and behavioral changes that parallel the inferior performance, to hypotheses concerned with the differential interaction of neo- $T_{3}$ and $-T_{4}$ animals with their rearing environment (Schapiro, 1968, 1971).

We have previously reported an elevated rate of ambulation and rearing in an open-field situation in adult neo- $\mathrm{T}_{3}+\mathrm{T}_{4}$ rats (Sjödén \& Söderberg, 1976, in press). On this basis, we have suggested that such rats would be inferior to controls in learning tests where a high rate of locomotor-exploratory reactions competes with behavior required for efficient learning of the task at hand. Thus, we have predicted an interaction of the effects of neonatal $\mathrm{T}_{3}+\mathrm{T}_{4}$ treatment with the difficulty of the learning test, based on the assumption that the more difficult the test, the more would competing exploratory reactions interfere with efficient learning (Sjödén \& 
Söderberg, in press). As a preliminary measure of test difficulty, the number of trials to a predetermined criterion was suggested. In the passive avoidance test (Davenport \& Gonzalez, 1973; Stone \& Greenough, 1975), the neo- $T_{4}$ rats would be at a disadvantage, since their high rate of exploring the environment would rapidly bring them to the part of the testing apparatus where shock was administered during training. Our observation of a slower rate of habituation of locomotor exploration in a new surrounding (Sjödén \& Söderberg, in press) would work in the same direction with respect to learning scores.

The present investigation was an attempt to further test the hypothesis of a neonatal Thyroid Hormone by Rearing Conditions interaction on adult behavior and learning in rats (Sjödén \& Söderberg, 1976, in press). Thus, enriched preweaning rearing conditions are expected to counteract the effects, whatever they are, of neonatal hormone stimulation on adult learning. The choice of learning test was dictated by the aim to use a relatively simple situation, at least in comparison to the often used Hebb-Williams maze (Eayrs, 1964; Pelt, 1972). If, as stated by Davenport and Gonzalez (1973), only relatively complex tests of learning should be used, with the rationale that only these are "sensitive" enough to detect "learning deficits" in adult neo- $T_{4}$ rats, other effects (e.g., a facilitated performance) in simpler learning situations are easily overlooked. An attempt was made to include the variable of test difficulty within the learning situation. To that end, an initial position discrimination (original training: OT) and three subsequent position reversals ( $R 1, R 2$, and $R 3$ ) were employed. The initial position discrimination is rapidly acquired by rats, whereas the first reversal usually requires a large number of trials (Mackintosh, McGonigle, Holgate, \& Vanderver, 1968). Thus, it was expected that the direction and magnitude of the difference between neo- $T_{3}+T_{4}$ rats and controls would depend on the particular phase of the experiment. If the reasoning in terms of competing exploratory reactions presented above holds for these rats, two patterns of effects would be possible. (1) $T_{3}+T_{4}$-treated rats would perform identically to controls in OT, would perform worse in R1, and would show a diminishing degree of inferior performance in R2 and R3. (2) $T_{3}+T_{4}$-treated rats would perform better than controls in OT, identically in $\mathrm{R} 1$, and evidence a progressively better performance than controls in R2 and R3.

\section{METHOD}

\section{Subjects}

Eight nulliparous Wistar females (Rattus norvegicus), approximately 100 days old, purchased from K. E. Møllegaard, Denmark, were bred to Wistar males at our laboratory. All of them delivered litters consisting of from 7 to 13 pups $(\bar{X}=10.9)$ within $24 \mathrm{~h}$ of each other. Within $24 \mathrm{~h}$ after birth, 64 pups (32 males and 32 females) were randomly chosen from the total group born $(\mathrm{N}=87)$ and randomly redistributed to the females, with the restriction that each litter consist of 4 males and 4 females. The redistribution was performed in order to balance possible genetic and prenatal differences between biological litters. The possibility of differential litter effects due to the postnatal interaction of females with pups (Henderson, 1963, 1967; King, 1969, 1970) was controlled by a partial hierarchical analysis of variance (see below).

\section{Injections}

On Day 4 post partum (Day 1 = day of birth), the pups from four randomly chosen litters were given intraperitoneal injections of a mixture of $25 \mu \mathrm{g}$ 1-tri-iodothyronine $\left(\mathrm{T}_{3}\right)$ and $100 \mu \mathrm{g}$ 1-thyroxine-sodium $\left(\mathrm{T}_{4}\right)$ (Nyegaard \& Co., Oslo, Norway) dissolved in $.1 \mathrm{ml}$ saline vehicle. The rationale for employing this particular mixture of hormones as well as evidence showing the equivalence of the $T_{3}+T_{4}$ mixture to similar doses of either $T_{3}$ or $\mathrm{T}_{4}$ alone have been given elsewhere (Sjödén \& Söderberg, in press). The remaining four litters received an equivalent amount of the saline vehicle.

\section{Rearing Conditions}

Two $T_{3}+T_{4}$ litters $(T)$ and two control litters (C) were reared in an enriched (E) environment and two $T$ and two $C$ litters were reared in an impoverished (I) environment during the preweaning period. Each litter was housed in a separate E or I cage. The use of a preweaning manipulation of rearing conditions is based on a proposition by Schapiro (1971) that the most sensitive period for affecting the central nervous system by environmental experiential means is before weaning (cf. Malkasian \& Diamond, 1971). The dams were placed in their respective environmental conditions 3 days prior to expected delivery and were provided with strips of paper, for use as nesting material. The $\mathrm{E}$ condition consisted of wire-mesh cages $(32 \times 51 \times 30 \mathrm{~cm})$ provided with numerous playthings such as a ladder, a small activity wheel, and a piece of plastic tubing. The animals in each $E$ cage could see the other $\mathrm{E}$ cages and the rest of the room. The I condition consisted of opaque plastic boxes $(33 \times 25 \times 16 \mathrm{~cm})$ with wire-mesh tops. The $E$ cages were placed directly on the type of bedding material which was provided in the I condition. ${ }^{1}$

Food (Lab Chow 213 and 210, AB Anticimex, Sollentuna, Sweden) and tap water were provided ad lib. All rats were placed on a 12-h-on, 12-h-off (lights on at $0600 \mathrm{~h}$ ) lighting schedule in a room thermostatically maintained between $21^{\circ}$ and $24^{\circ} \mathrm{C}$. All behavioral tests were carried out during the light portion of the 24-h period. The cages were cleaned 15 days after parturition. The mother and pups remained in their cages until 23 days after delivery, when the young were weaned and placed in individual cages $(16.5 \times 22.5 \times 13.5 \mathrm{~cm})$.

\section{Behavioral Test}

At 90 days of age, an open-field test was performed, the results of which have been reported elsewhere (Sjödén \& Söderberg, in press).

Starting at 165 days, the animals were trained in a task of position discrimination, requiring that they choose the correct path in a $\prod$-shaped water-maze (i.e., swam to the right or left arm)(cf. Smart \& Adlard, 1974). A self-correction procedure was used throughout. The maze consisted of a white-painted tank with internal dimensions: length $105 \mathrm{~cm}$, width $45 \mathrm{~cm}$, and height $40 \mathrm{~cm}$. Two white U-shaped inserts were placed alongside one of the long sides of the tank, so that $11-\mathrm{cm}$-wide pathways were formed. The correct arm ended with a ladder, by means of which the animal was allowed to get out of the water into a regular empty housing cage. The rat was placed in the start arm, facing the choice area, and on the first trial was allowed a free choice (both arms were open and ended with ladders). The sub- 
sequent position discrimination training (original training: OT) was performed with the initially preferred arm as the correct one. The other arm of the maze was closed. The water was $35 \mathrm{~cm}$ deep and varied between $17^{\circ}$ and $19^{\circ} \mathrm{C}$ during a training session. Ten trials a day were given, with an intertrial interval of approximately $60 \mathrm{sec}$, until 10 consecutive correct responses (irrespective of day) had been made. At that time, the correct position was reversed and the identical training was instituted for the first position reversal (R1), which was followed by a second and a third (R2 and R3) after the rat had reached the same criterion as above. When the animal swam into the incorrect arm, an error was scored when the animal left the choice area with its entire body including the tail. After each training session, the rats were placed close to carbon lamps for $12 \mathrm{~min}$ in order to facilitate drying of the fur.

\section{RESULTS}

To control for postnatal litter effects, partial hierarchal analyses of variance were performed with Thyroxine (2) by Rearing Conditions (2) by Sex (2) as crossed factors and Litters (2) nested within Thyroxine-Rearing Condition combinations (Harter \& Lum, Note 1, pp. 101-103). Confirming the results of previous workers (Denenberg \& Kline, 1964; King, 1969, 1970), no significant litter effects were obtained, so the subsequent analyses were performed on straight factorial or on split-plot designs with Reversals (4) or Successive Criteria (10) (see below) as repeated measurement factors (Kirk, 1968). When appropriate, simple main effects analyses were performed with a pooled within-cell error variance (Kirk, 1968, pp. 264-265). The following presentation includes all main effects and the highest obtained order interactions involving the Throxine variable.

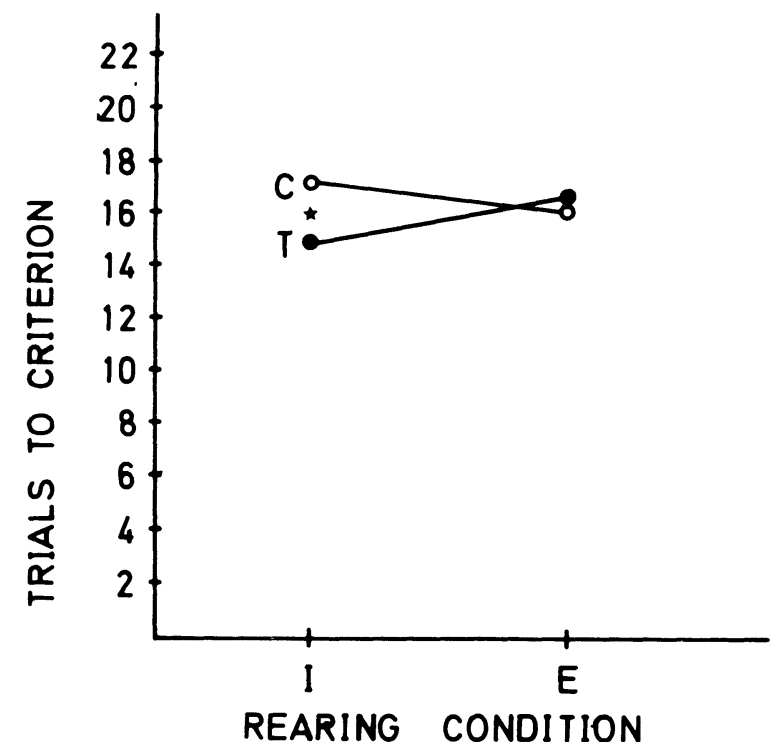

Figure 1. Mean number of trials to criterion of neonatally thyroid hormone $(T)$ and saline $(C)$ treated rats reared under impoverished (I) and enriched (E) preweaning conditions. ${ }^{*} \mathbf{p}<.05$.
Table 1

Mean Final Error Trial to Criteria 1 and 10 in Each Reversal Phase

\begin{tabular}{llllrrrrr}
\hline & \multicolumn{2}{c}{ OT } & \multicolumn{2}{c}{ R1 } & \multicolumn{3}{c}{ R2 } & \multicolumn{2}{c}{ R3 } \\
Group & C1 & C10 & C1 & C10 & C1 & C10 & C1 & C10 \\
\hline \multicolumn{10}{c}{ Males } \\
TI & 0 & 3.8 & 5.1 & 6.0 & 3.6 & $3.6^{*}$ & 2.6 & 4.0 \\
CI & 0 & 4.0 & 3.9 & 5.3 & 4.6 & 8.1 & 3.9 & 6.9 \\
TE & 0 & 4.5 & 4.4 & 10.8 & 3.8 & 7.1 & 3.9 & 5.3 \\
CE & 0 & 3.1 & 4.0 & 8.9 & 4.8 & 8.0 & 3.3 & 6.8 \\
& & & \multicolumn{7}{c}{ Females } & & & \\
TI & 0 & $3.4 *$ & $6.0^{*}$ & 8.4 & 3.1 & 8.6 & 3.1 & 4.0 \\
CI & 0 & 9.9 & 3.9 & 9.9 & 2.8 & 10.8 & 2.4 & 6.0 \\
TE & 0 & 4.8 & 3.1 & 12.6 & 2.5 & 4.1 & 2.0 & 5.5 \\
CE & 0 & 5.8 & 4.3 & 8.0 & 2.8 & 4.6 & 1.9 & 5.3 \\
\hline
\end{tabular}

${ }^{*} p<.05, d f=14, t_{\text {crit }}=1.761$ for TI-CI or TE-CE difference.

A significant effect of Reversals appeared for the number of trials to criterion $[\mathrm{F}(3.168)=7.5, \mathrm{p}<.05]$, depending upon a negative transfer between OT and $\mathrm{R} 1$ and positive transfer thereafter. This indicates that the difficulty of different phases of the maze test varied in an expected manner (Mackintosh et al., 1968). Thyroxine interacted with Rearing Conditions $[F(1.56)=5.4, p<.05]$ due to a significantly smaller number of trials to criterion in the $T$ as compared to the $\mathrm{C}$ group in the I condition only $[F(1.56)=7.4, p<.05]$ (Figure 1). A more detailed analysis of data for Criteria 1 and 10 for each reversal phase is given in Table 1 (see below). An analysis of the number of errors to criterion showed a significant effect of Reversals only $[F(1.56)=50.8$, $\mathrm{p}<.05$ ]. Since a number of rats were observed to commit several errors within one trial, the number of error trials to criterion (i.e., the number of trials on which at least one error was committed) was analyzed. The results paralleled those for the number of errors to criterion, indicating an equal degree of self-correction after an incorrect response in all groups.

The mean final error trial for each successive criterion of 1-10 consecutive correct responses was computed. This analysis was based on a value for each individual animal, showing the trial number on which the last error was committed before running off from 1 to 10 consecutive correct responses (cf. Bronstein \& Spear, 1972). Analysis of variance was carried out for OT, R1, R2, and R3 separately, with $\mathrm{p}<.05$ throughout. In each analysis, only the interaction of the highest order is specified below. Table 1 presents the results for Criteria 1 and 10 in each reversal phase with corresponding $t$ tests for the various Thyroxine-Rearing Condition treatments. One-tailed $t$ tests were run in view of the directed nature of the hypotheses proposed concerning the Thyroid Hormone by Rearing Conditions interaction 
and those concerning the pattern of results across Reversals.

The analysis of variance showed a significant Thyroxine by Sex by Criteria interaction $[F(9.504)=$ $3.9, p<.05$ ] during OT. An analysis of simple main effects showed this to be due to higher mean final error trial scores in the female $\mathrm{C}$ than in the female $\mathrm{T}$ group for Criteria 8-10. During R1, a Thyroxine by Rearing Conditions by Criteria interaction $[\mathrm{F}(9.504)=$ $2.3, \mathrm{p}<.05$ ] was significant, due to higher scores for the TE group than for the $\mathrm{CE}$ group for Criteria 9-10 and no difference between TI and CI groups. In the R3 phase, an interaction of Thyroxine with Criteria appeared in a similar form as for OT $[F(9.504)=3.4, p<.05]$, resulting from a significantly better performance in the $\mathrm{T}$ as compared to the $\mathrm{C}$ group for Criterion 10 only.

The number of initial perseverative responses made in the direction of the previously correct alternative before reaching Criterion 1 in each new reversal phase was analyzed. This analysis was performed for the transition from OT to R1, R1 to R2, and R2 to R3 separately. Means for the various Thyroxine-Rearing Conditions treatment groups and corresponding $t$ tests are presented in Table 2.

An interaction of Thyroxine with Rearing Conditions appeared for the OT-R1 data $[\mathrm{F}(1,56)=4.3$, $\mathrm{p}<.05]$ due to a significant $\mathrm{TI}>\mathrm{CI}$ difference (TI, 6.9; CI, 4.6), $[\mathrm{F}(1,56)=5.6, \mathrm{p}<.05]$ and no TE/CE difference (TE, 4.6; CE, 5.1). In the R2-R3 transition, there was a Thyroxine by Rearing Conditions by Sex interaction $[F(1.56)=4.5, p<.05]$ due to a significant $\mathrm{CI}>\mathrm{TI}$ difference among the males only $[\mathrm{F}(1.56)=7.1, \mathrm{p}<.05]$.

\section{DISCUSSION}

In contrast to previous reports (Davenport \& Gonzalez, 1973; Eayrs, 1964), no clear-cut deficiency of maze learning performance was seen in neo- $T_{3}+T_{4}$ rats. The thyroid hormone-stimulated group was inferior to the control group only during R1 (Table 1), apparently due to an initial perseveration of the alternative reinforced during the OT phase (Table 2). However, in all of the other three phases (OT, R2, and R3), neo- $T_{3}+T_{4}$ treatment caused better performance, depending on sex, rearing condition, and the particular measure of performance. Overall, the thyroid-treated impoverished rats performed better on the trials to criterion measure than the impoverished controls. This pattern of effects confirms the hypothesis put forward earlier, i.e., the more difficult the task, the less well neo- $T_{3}+T_{4}$ groups will perform, and the easier the task, the better they will perform in comparison to $\mathrm{C}$ groups. This illustrates that the concept of "inferior learning ability" as applied to neo- $T_{3}+T_{4}$ rats is not appro-
Table 2

Mean Number of Perseverative Responses to Criterion 1 in Each Reversal Phase

\begin{tabular}{clcl}
\hline Group & R1 & R2 & R3 \\
\hline & & Males & \\
TI & $6.9 * *$ & 5.5 & $3.0^{* *}$ \\
CI & 4.1 & 5.9 & 5.5 \\
TE & 5.5 & 4.5 & 4.3 \\
CE & 4.6 & 5.6 & 4.0 \\
& & Females & \\
TI & $7.0^{*}$ & 5.1 & 4.6 \\
CI & 5.1 & 4.0 & 4.0 \\
TE & $3.6^{*}$ & 4.5 & 2.4 \\
CE & 5.6 & 3.8 & 3.0 \\
\hline
\end{tabular}

${ }^{*} p<.10, d f=14, t_{c r i t}=1.345$ for TI-CI or TE-CE difference. ${ }^{* *} p<.05, d f=14, t_{\text {crit }}=1.761$ for TI-CI or TE-CE differ ence.

priate. Their performance is not only determined by their neonatal hormone condition, but also by the difficulty of the learning test used.

The hypothesis of an interaction of hormone with preweaning rearing conditions is at least partially supported by the fact that the superior trials-tocriterion performance seen among $T$ rats in the $I$ condition was not evident in the $\mathrm{E}$ condition. The pattern of mean final error trial results in Table 1 also shows the same trend. Also, the TI-CI differences of perseverative initial $\mathrm{R} 1$ and $\mathrm{R} 3$ responses in Table 2 do not have any counterparts in the $\mathrm{E}$ groups. Thus, in these respects, preweaning enrichment counteracted the effects of neo-T $T_{3}+T_{4}$ administration. These results parallel those previously found in the open field (Sjödén \& Söderberg, in press), and those reported by Ray and Hochhauser (1969) for prenatal growth hormone effects on adult learning, as well as those by Levitsky and Barnes (1972), who found that the behavioral effects of early protein deficiency can be counteracted by giving animals additional environmental stimulation.

Previous reports on simple maze learning in neo- $\mathrm{T}_{3}$ (Schapiro, 1968) and neo- $\mathrm{T}_{4}$ rats (Stone \& Greenough, 1975) have yielded variable results. The procedural details of the Schapiro study (1968) are severely lacking, as is information on the number of rats used and a statistical test of the results. Thus, the inferior performance of the neo- $T_{3}$ group in a Y-shaped water maze and the Lashley III maze reported by Schapiro (1968) is very difficult to judge with respect to magnitude and significance. Stone and Greenough (1975) obtained no effects of neo- $T_{4}$ treatment in a simple geotactic discrimination task or on Day 1 of Lashley III maze testing, whereas a neo- $\mathrm{T}_{4}$-produced deficit was evident in retention and reversal testing on Day 2, thus paralleling the present results.

The reason for the observed differences of learning test performance in the present study could only be 
suggested from the results obtained. From the mean final error trial data, it seems clear that, when the $T$ group performs better than the $C$ group, the $T$ rats surpass the $C$ rats for Criteria 8-10. This indicates that the $T$ group shows a superior ability to string together long sequences of correct responses as compared to the $\mathrm{C}$ group. However, at the beginning of the R1 phase, the TI group had difficulty in changing to the correct $\mathrm{R} 1$ alternative. Thus, it appears that the neo- $T_{3}+T_{4}$ group shows a superior ability to inhibit incorrect responses following long sequences of correct responding when in the relatively easy OT, $R 2$, and $R 3$ phases. On the other hand, in the $\mathrm{R} 1$ phase, the $\mathrm{T}$ group is less able to inhibit initial responses to the previously correct (OT) alternative. The conclusion that in certain types of tests, neo- $\mathrm{T}_{4}$ rats may be less able to inhibit incorrect responses in the face of aversive consequences, is supported by their deficient learning of passive avoidance behavior (Davenport \& Gonzalez, 1973; Stone \& Greenough, 1975). Also, habituation to the positive characteristics of the incorrect alternative may be slower in neo- $T_{3}+T_{4}$ rats (cf. Sjödén \& Söderberg, in press). Interestingly, these conclusions are similar to those reached by Bronstein and Spear (1972) when comparing spatial discrimination learning in juvenile and adult rats. They found juveniles to have a higher mean final error trial score than adults, particularly for Criteria 5-10.

\section{REFERENCE NOTE}

1. Harter, H. L., \& Lum, M. D. Partially hierarchal models in the analysis of variance. WADC Technical Report 55-33, Wright-Patterson AFB, Ohio, 1955.

\section{REFERENCES}

Bakke, J. L., \& Lawrence, N. Persistent thyrotropin insufficiency following neonatal thyroxine administration. Journal of Laboratory and Clinical Medicine, 1966, 67, 477-482.

Bakke, J. L., LaWrence, N., \& Wilber, J. F. The late effects of neonatal hyperthyroidism upon the hypothalamicpituitary-thyroid axis in the rat. Endocrinology, 1974, 95, 406-411.

Balázs, R., Kovács, S., Cocks, W. A.. Johnsoñ, A. L., \& EAYRS, J. T. Effect of thyroid hormone on the biochemical maturation of rat brain: Postnatal cell formation. Brain Research, 1971, 25, 555-570.

Bronstein, P. M., \& Spear, N. Acquisition of a spatial discrimination by rats as a function of age. Journal of Comparative and Physiological Psychology, 1972, 78, 208-212.

Davenport, J. W., \& Gonzalez, L. M. Neonatal thyroxine stimulation in rats: Accelerated behavioral maturation and subsequent learning deficit. Journal of Comparative and Physiological Psychology, 1973, 85, 397-408.

Davenport, J. W., Hagquist, W. W., \& Hennies, R. S. Neonatal hyperthyroidism: Maturational acceleration and learning deficit in triiodothyronine-stimulated rats. Physiological Psychology, 1975, 3, 231-236.
Denenberg, V. H., \& Kine, N. J. Stimulus intensity versus critical periods: A test of two hypotheses concerning infantile stimulation. Canadian Journal of Psychology, 1964, 18, 1-5.

EAYRS, J. T. Effect of neonatal hyperthyroidism on maturation and learning in the rat. Animal Behaviour, 1964, 12, 195-199.

EAYRS, J. T. Developmental relationships between brain and thyroid. In R. P. Michael (Ed.), Endocrinology and human behaviour. London: Oxford University Press, 1968. Pp. 239-255.

EAYRS, J. T., \& Holmes, R. L. Effect of neonatal hyperthyroid ism on pituitary structure and function in the rat. Journal of Endocrinology, 1964, 29, 71-81.

HENDERSON, N. D. Methodological problems in measuring ambulation in the open field. Psychological Reports, 1963, 13, 907-912.

Henderson, N. D. Early shock effects in the Balb/c mouse. Journal of Comparative and Physiological Psychology, 1967, 64, 168-170.

KING, D. L. The effect of early experience and litter on some weight and maturational variables. Developmental Psychology, 1969, 1, 576-584.

KING, D. L. Effect of early experience and litter on some emotionality variables in the rat. Journal of Comparative and Physiological Psychology, 1970, 73, 436-441.

KIRK, R. E. Experimental design: Procedures for the behavioral sciences. Belmont, Calif: Brooks/Cole, 1968.

LÁT, J., \& Gollovì-HÉMon, E. Permanent effects of nutritional and endocrinological intervention in early ontogeny on the level of nonspecific excitability and on lability (emotionality). Annals of the New York Academy of Sciences, 1969, 159, 710-720.

LeVITSKY, D. A., \& BARNes, R. H. Nutritional and environmental interactions in the behavioral development of the rat: Long-term effects. Science, 1972, 176, 68-71.

Mackintosh, N. J., McGonigle, B., Holgate, V., \& VANDERVER, V. Factors underlying improvement in serial reversal learning. Canadian Journal of Psychology, 1968, 22, 85-95.

Malkasian, D. R., \& Diamond, M. C. The effects of environmental manipulation on the morphology of the neonate rat brain. International Journal of Neuroscience, 1971, 2, 161-170.

Nicholson, J. L., \& Altman, J. The effects of early hypo- and hyperthyroidism on the development of rat cerebellar cortex: I. Cell proliferation and differentiation. Brain Research, 1972, 44, 13-23. (a)

Nicholson, J. L., \& Altman, J. The effects of early hypo- and hyperthyroidism on the development of rat cerebellar cortex: II. Synaptogenesis in the molecular layer. Brain Research, 1972, 44, 25-36. (b)

PELT, F. L. The effects of neonatal treatment with methylthiouracil and triiodothyronine on physical and behavioural development. Doctoral dissertation, University of Rotterdam, 1972.

Rastogi, R. B., \& Singhal, R. L. Neonatal hyperthyroidism: Alterations in behavioural activity and the metabolism of brain norepinephrine and dopamine. Life Sciences, 1976, 18, 851-858.

RAY, O. S., \& HochHAUSER, S. Growth hormone and environmental complexity effects on behavior in the rat. Developmental Psychology, 1969, 1, 311-317.

Rosenzweig, M. R., Bennett, E. L., \& Diamond, M. C. Brain changes in response to experience. Scientific American, 1972, 226, 22-29.

SCHAPIRo, S. Metabolic and maturational effects of thyroxine on the infant rat. Endocrinology, 1966, 78, 527-532.

SCHAPIRo, S. Some physiological, biochemical, and behavioral consequences of neonatal hormone administration: Cortisol and thyroxine. General and Comparative Endocrinology, 1968, 10, 214-228.

SCHAPIRo, S. Hormonal and environmental influences on rat brain development and behavior. In M. B. Sterman, D. J. McGinty, \& A. M. Adinolfi (Eds.), Brain development and behavior. New York: Academic Press, 1971. Pp. 307-334.

SChapiro, S., \& Norman, R. J. Thyroxine: Effects of neonatal 
administration on maturation, development, and behavior. Science, 1967, 155, 1279-1281.

SChreiber, V., \& KMentová, V. Thyroxine in the early postnatal period: Minimal changes in thyroid function. Neuroendocrinology, 1965/66, 1, 121-128.

SjöbéN, P. O., \& SöDERBERG, U. Effects of neonatal thyroxine stimulation on adult open-field behavior and thyroid activity in rats. Physiological Psychology, 1976, 4, 50-56.

SiöDÉN, P. O., \& SöDERBERG, U. Effects of neonatal thyroid hormone stimulation and differential preweaning rearing on open-field behavior in adult rats. Developmental Psychobiology, in press.

Smart, J. L., \& Adlard, B. P. F. A water-maze test of learning ability for guinea-pigs. Laboratory Animals, 1974, 8, 311-315.

Stone, J. M., \& Greenough, W. T. Excess neonatal thyroxine: Effects on learning in infant and adolescent rats. Developmental Psychobiology, 1975, 8, 479-488.

\section{NOTE}

1. Since the environmental manipulation was carried out before weaning, the complete social isolation employed after weaning by Rosenzweig, Bennett, and Diamond (1972) was not deemed appropriate. Raising pups in differently sized litters would seriously confound the differential rearing variable with nutritional differences. Although considerably smaller, the present I condition is more like a normal laboratory rearing cage than the social isolation provided by Rosenzweig et al. (1972). However, because no inanimate objects were in the cages and visual sensory experience was restricted, the term "impoverished" seems the most appropriate.

(Received for publication March 23, 1976; revision accepted October $1,1976$. 